\title{
METODOLOGIA DA UNIDADE PADRÃO DE TEMPO (UP) EM UMA INDÚSTRIA DE CONFECÇÕES
}

\section{STANDARD UNIT TIME (UP) METHODOLOGY IN A CLOTHING INDUSTRY}

\author{
Valdemar Dias dos Santos ${ }^{1}$
}

Submetido em: 14/07/2021

e1217 Aprovado em: 14/08/2021

https://doi.org/10.47820/acertte.v1i2.17

\section{RESUMO}

Diante da realidade vivida pelas empresas, em virtude da abertura do mercado e consequentemente da concorrência por ela imposta, os controles de quantidade produzida, custo da produção, ociosidade, capacidade produtiva e tudo mais relacionado à eficiência, se tornaram questão de sobrevivência para quem quer se manter no mercado. No setor de confecções essa realidade não é diferente. Produtos de diversas origens e características se apresentam no mercado e pressionam preços e critérios de desempenho. Especialmente na região Norte do Estado do Paraná. Em comum, observa-se a preocupação dessas empresas em estabelecer o preço adequado e competitivo para gerar sobrevivência e capacidade de crescimento. Para isso, a busca da identificação do quanto se gasta para produzir concentra uma vasta gama dos esforços.

PALAVRAS-CHAVE: Custo de produção. Tempo na produção e unidade padrão de produção

\section{ABSTRACT}

Given the reality experienced by companies, due to the opening of the market and consequently the competition imposed by it, the controls of produced quantity, production cost, idleness, productive capacity and everything else related to efficiency, have become a matter of survival for those who want stay in the market. In the clothing sector, this reality is no different. Products from different origins and characteristics present themselves on the market and put pressure on prices and performance criteria. Especially in the northern region of the State of Paraná. In common, they are concerned with establishing the appropriate and competitive price to generate survival and growth capacity. For this, the search to identify how much is spent to produce concentrates a wide range of efforts.

KEYWORDS: Production cost. Time in production and standard production unit

\section{INTRODUÇÃO}

Diante disso, nunca como agora a contabilidade de custos e os métodos de custeio foram tão valorizados. Nota-se que não basta mais se formar o preço do produto, é preciso saber se este preço é aceito pelo mercado, caso não seja, é necessário torná-lo aceitável e gerador de lucratividade. Somente através de um sistema de custo, que possa proporcionar conhecimento, controle e visão da atividade produtiva e que venha contribuir para gerar capacidade de adaptação, para garantir a sobrevivência no atual cenário. Porém, deve-se observar que os vários sistemas de custos existentes servem para diversas finalidades, cabendo a empresa encontrar o que melhor the proverá de informações e controles para tomadas de decisões.

Dessa forma, trataremos neste artigo dos problemas de custos enfrentados pelas empresas do setor de confecções, partindo da necessidade de se identificar uma metodologia adequada para a

\footnotetext{
${ }^{1}$ UNIFAHE - Faculdade de Administração, Humanas e Exatas

ACERTTE - Administração, Ciências Contábeis, Economia, Turismo, Tecnologia e Engenharia
} 


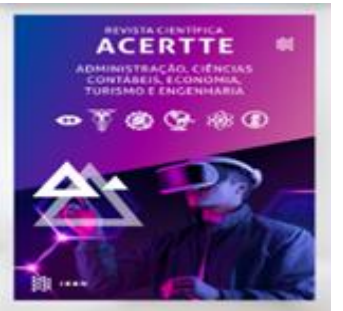

padronização da produção. Esse aspecto assume relevância quando se verifica que esses problemas se intensificam quando se faz uma análise pontual do setor especificamente na área de atuação das empresas que prestam serviço de facção, ou seja, junção das partes já cortadas que formaram a peça através da costura. Nesse sentido, neste estudo busca-se analisar os problemas observados em uma empresa do setor na adoção de uma metodologia de custeio, bem como identificar formas de melhor ajustar a metodologia à sua dinâmica competitiva.

De acordo com dados da Federação das Indústrias do Paraná (Fiep: 2020), o segmento industrial de confecção, têxtil e artefatos em couro é composto por 4.738 empresas e gera 65,9 mil empregos. É o terceiro segmento da indústria do Paraná em geração de empregos, perdendo apenas para o ramo alimentício e da construção civil onde empresas disputam espaço no mercado local, regional e nacional.

\section{PROCEDIMENTOS}

Para atingir os objetivos estabelecidos nesse artigo, buscou-se inicialmente realizar uma revisão da literatura envolvendo os métodos de custeio, os quais permitem as empresas controlarem e organizarem as suas atividades produtivas, possibilitando que empresários venham a enxergar nestas não apenas o consumo de recursos da empresa, mas sim potenciais, que uma vez bem explorados permitam uma vantagem competitiva no mercado globalizado. Em um segundo momento, analisou-se a questão do custeio de forma detalhada, por intermédio de um estudo de caso, em que se procurou identificar a metodologia adotada e as dificuldades enfrentadas.

Para isso foi feita uma coleta de dados através da observação na área de produção da empresa, chão de fábrica, acompanhando todo o processo produtivo de algumas ordens de produção, bem como perguntas a operadores e encarregados dos setores produtivos. As informações a respeito de controles de produção, como planilhas, apontamento de tempo e resultados de eficiência da fábrica foram conseguidos através de consultas a arquivos e documentos, bem como através de entrevistas com o responsável geral pela produção na empresa.

No entanto, não há a pretensão de esgotar ou resolver todos os problemas tratados neste artigo, no tocante ao setor da facção, mesmo porque o artigo retrata a realidade de uma única empresa do setor. Porém, a intenção é levantar por intermédio deste estudo de caso novas argumentações e discussões que possam contribuir para que as empresas deste setor venham a identificar novos métodos de tornarem suas atividades produtivas e seus custos mais competidos e porque não dizer mais eficazes.

\section{REVISÃO DA LITERATURA}

$A$ equação $P=L+C$, onde $P$ é igual a preço, $L$ é igual a lucro e $C$ é igual a custo, por muito 


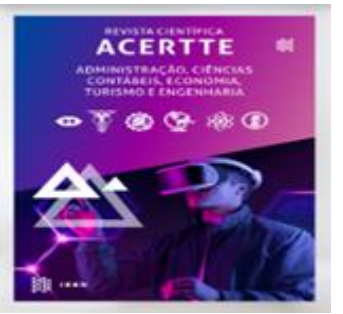

tempo foi usada para determinação dos preços de produtos e serviços no mercado, pois satisfazia totalmente a necessidade do proprietário de obter lucro e da empresa de cobrir seus custos. Com a abertura do mercado, através da globalização, teve seu uso limitado drasticamente. Sua aplicação passou a acontecer somente em empresas que operam em regime de monopólio, sendo a única restrição a essas empresas o poder de compra dos consumidores ou uma eventual intervenção do governo. (IOB 2003).

O advento da abertura do mercado estabeleceu a necessidade de rever rapidamente como determinar esses preços. O próprio mercado começou a exigir que os preços determinados para os produtos e serviços revelassem um nível de competitividade entre as empresas. Dessa forma a equação passou a ser $\mathrm{L}=\mathrm{P}-\mathrm{C}$, ou seja, além das empresas determinarem preços compatíveis com a concorrência, do contrário seriam engolidas, precisavam mais do que nunca, para manterem sua lucratividade, reduzirem seus custos.

Definir preço para produtos e serviços se tornou uma tarefa desafiadora, que exige muito talento, visão de mercado e acima de tudo conhecimento da empresa. Nesse Sentido, conhecer a empresa e seu potencial se tornou o fator decisivo para superação dos dois princípios básicos da definição do preço dos produtos e serviços. (IOB 2003):

1 Princípio: Manter um nível de preços para produtos e serviços que seja competitivo com a concorrência;

2- Princípio: Manter um nível de rentabilidade adequado entre o preço do produto e os seus custos.

A princípio parece simples, porém, exige uma busca constante de aperfeiçoamento de processos, pois se o primeiro princípio limita o preço final do produto, resta então atacar o grande vilão, aquele que acaba roubando a rentabilidade do produto, ou seja, o custo. Enquanto muitas empresas se limitam a tentar minimizar as limitações de suas operações de fabricação, outras com uma visão mais otimista, veem nestas limitações a possibilidade de torná-las fonte de vantagem competitiva.

\subsection{A influência dos processos produtivos na competitividade das empresas}

$\mathrm{O}$ que tem feito a diferença em termos de competitividade entre as empresas na determinação de seus preços de produtos e serviços, não tem sido melhores projetos na elaboração de seus produtos, nem mesmo dinamismo em marketing criativo. O que as empresas têm sentido em alguns concorrentes é a vantagem competitiva que a capacidade geral de fabricação superior lhes tem proporcionado. (HAYES \& WHEELWRIGHT, 1998). Com o passar do tempo, poucas empresas valorizaram e investiram adequadamente em seus processos produtivos, voltaram suas atenções e esforços principalmente para a parte administrativa da empresa, para setores como o de vendas, marketing e financeiro. Isso fez com que estas 


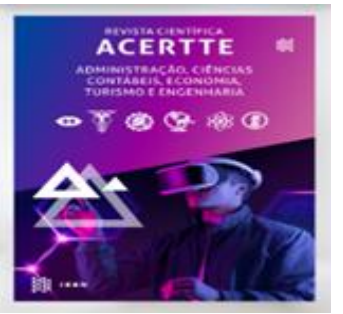

empresas acabassem por negligenciarem suas organizações de fabricação, por anos seguidos, sentindo agora, como é difícil e demorado recuperar a excelência perdida de produção, principalmente atuando em mercados tão competitivos.

O atual cenário competitivo vem provocando mudanças de visão da alta gerência das empresas, que passaram a visualizar a grande vantagem competitiva que seus processos produtivos poderiam trazer para a empresa. Em consequência disso a necessidade de rever processos fabris, investir constante em tecnologia de produção e na área de recursos humanos se tornou obrigatória, em busca da meta estabelecida: "a redução dos custos de fabricação" sem, contudo, perder a qualidade dos produtos ou serviços oferecidos.

A exigência da sobrevivência tem feito que as empresas busquem tornar suas organizações mais integradas, fazendo da área de produção um suporte para as outras áreas da empresa, principalmente para a engenharia e marketing. Desta forma, quando ocorre desenvolvimento de novos produtos ou políticas de marketing, já se sabe como pode ser explorada as capacidades produtivas e se há possibilidade de flexibilização de produção para atender tal demanda.

Tudo isso, porém, não acontece da noite para o dia, é preciso ser persistente e acima de tudo ter paciência, pois mudar a cultura que a empresa por anos cultivou requer muita comunicação e objetivos transparentes e concisos. A integração de funções tem de ser buscada a todo momento, rompendo conceitos tradicionais de gerência. É preciso deixar bem claro e forçar toda a organização a entender que o desafio das mudanças trará uma vantagem competitiva sobre a concorrência, permitindo assim a sobrevivência e o desenvolvimento da empresa num cenário altamente competitivo.

\subsection{Custos uma questão de sobrevivência para as empresas}

Todo o desenvolvimento e aperfeiçoamento provenientes da busca da vantagem competitiva por intermédio da gestão dos processos fabris e da integração dos mesmo com o resto da organização, visa na realidade a redução do custo dos produtos ou serviços através da eficácia do desempenho de processos. Dentro desta ótica o custo se torna um parâmetro de desempenho e sobrevivência para as empresas.

Para Andersen (1995, p.30):

O ambiente competitivo sugere que a busca da lucratividade ideal se dará predominantemente através do controle e gerenciamento eficazes de custos. $O$ preço é agora ditado pelo mercado e a empresa deve ajustar seus custos e sua margem para chegar ao melhor preço de mercado. O processo decisório e a administração deverão tender cada vez mais para a utilização de custos e orçamento como dados fundamentais para a análise de decisões, sejam elas de caráter comercial, financeiro ou operacional, mas que cumpram a missão de chegar ao custo-alvo.

Podemos ressaltar que os sistemas de contabilidade de custos gerenciais não irão 


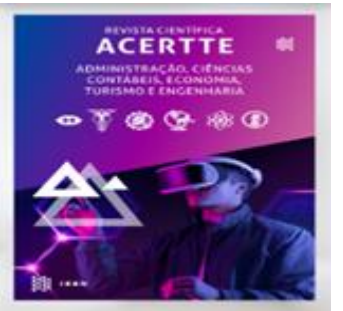

assegurar o sucesso do empreendimento. (JOHNSON \& KAPLAN, 1993). Mas certamente contribuirão para a sobrevivência das organizações, bastando para isso serem projetados para direcionar os investimentos de capital, coordenar as operações, julgar a eficiência de processos internos, avaliar a rentabilidade dos produtos oferecidos e fornecer metas aos seus gerentes.

Custos são todos os recursos utilizados no processo produtivo em busca do produto, despesas são todos os gastos que a empresa terá para comercializar este produto. Sendo que os custos são classificados em diretos, aqueles que estão diretamente vinculados aos produtos e permitem mensuração de consumo, e indiretos, aqueles que não estão diretamente vinculados aos produtos e não oferecem uma mensuração objetiva de consumo. Além de serem agrupados em relação ao produto como diretos ou indiretos, podem em relação aos níveis de produção serem também fixos, quando não mantém relação com quantidades produzidas ou variáveis, se a quantidade utilizada variarem com os níveis de produção.

Os elementos que formam os custos dos produtos de acordo com Martins (1998), são:

- Materiais diretos - diretamente consumidos para originarem os produtos;

- Mão-de-obra direta - participação do pessoal na transformação da matéria-prima em produto acabado;

- Custos indiretos de fabricação - aqueles custos que não se enquadram em materiais diretos nem em mão-de-obra direta, porém, são consumidos na produção geral dos produtos.

Quanto ao sistema de acumulação de custos, ou seja, a forma pela qual os custos de fabricação são acumulados e apropriado aos produtos, temos em decorrência da atividade produtiva da empresa dois sistemas básicos de acumulação de custos: (BACKER \& JACOBSEN, 1984)

- Produção por ordem ou encomenda - caracterizada por atividade de fabricação de produtos diferenciados, atendendo geralmente encomendas, onde os custos são alocados a ordem de produção.

- Produção contínua ou em série - caracterizada por atividade de fabricação de produtos uniformes, produzidos de maneira contínua, para venda direta ou para ficar em estoque, onde os custos são agrupados em um período de tempo e depois atribuídos aos produtos fabricados neste período.

$\mathrm{Na}$ apuração dos custos da fabricação podem ser utilizados diversos métodos de custeio. Sendo, porém, que dois deles tem se destacado no cenário de apuração de custos dos produtos e serviços nas empresas. O primeiro, chamado de método de custeio por absorção, consiste em apropriar aos produtos elaborados pela empresa, num determinado período de tempo, todos os custos incorridos no processo de fabricação. Esses podem estar diretamente vinculados ao produto ou podem se referir à tarefa de produção em geral e são alocados aos bem fabricados 


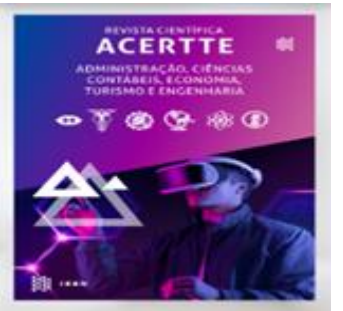

indiretamente, mediante ao uso de rateio. O segundo, chamado de método de custeio direto ou variável, por entender que a utilização do rateio, pelo seu grau de subjetividade, sempre induz a uma distribuição arbitrária dos custos fixos indiretos do período aos produtos produzidos, acabando por favorecer ou prejudicar a rentabilidade esperada do produto ou serviço, em virtude de ter recebido maior ou menor parcela destes custos fixos indiretos. Para resolver esse problema, o método de custeio direto ou variável passou a tratar estes custos fixos indiretos de fabricação como despesas fixas, independentemente da quantidade produzida de produtos ou serviços no período. Proporcionando a análise da margem de contribuição do produto para cobrir os custos fixos do período. (MARTINS, 1998)

Como exemplo de outros métodos de custeio temos o custeio integral, que nada mais é do que um prolongamento do conceito de custeio por absorção, o que se acrescenta é o tratamento das despesas com vendas e administração, que passam a serem consideradas como custos do período, e por isso alocadas aos produtos através de critérios de distribuição. (PADOVEZE, 1997), e também outro método de custeio que vem se destacando por ser uma poderosa ferramenta gerencial dentro da empresa, pois permite a administração um conhecimento detalhado das atividades desempenhadas para a elaboração do produto ou serviço, denominado custeio baseado em atividades ( $A B C)$. Para o $A B C$ não existem custos e despesas, é como se tudo fosse custo. Então tudo o que for vinculado diretamente com os produtos ou serviços (matérias-primas, materiais secundários, embalagens etc) são apropriados diretamente a eles, já os outros, inclusive mão-de-obra direta, mesmo que variável, são primeiro alocados às atividades, e destas aos produtos ou serviços. O método não se prende em alocar custos aos departamentos, e nem identificar qual parcela destes custos está na área de produção, eles são alocados diretamente às atividades. (IOB 2000)

Desta forma, o $A B C$ através de uma varredura no processo permite que os custos sejam investigados e relacionados às atividades necessárias para a obtenção do produto. $O$ modelo serve tanto para uma reengenharia no processo, cortando atividades que não são relevantes, pois não agregam valor ao produto ou serviço elaborados, como um identificador de onde os recursos estão sendo consumidos no processo. Uma vez relacionados os recursos com as atividades por meio de direcionadores de custo (cost drivers) e identificando quais atividades são necessárias para a elaboração do produto ou serviço, chega-se ao seu custo. Em um modelo simplificado poderíamos resumir o $\mathrm{ABC}$ conforme a figura 01 abaixo:

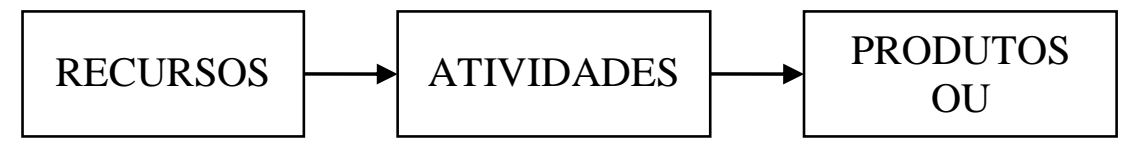

Figura 01 - fluxo do sistema de Custeio ABC (Fonte: GANTZEL \& ALLORA, 1996).

\subsection{A metodologia da unidade de produção (UP)}




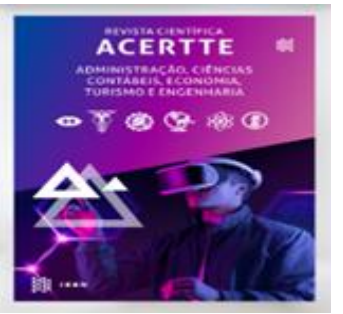

Nesta questão de como levantar o custo real dos produtos ou serviços produzidos, as empresas, principalmente as que produzem por encomendas, vêm buscando, através de ferramentas inovadoras, formas que possam corrigir distorções na distribuição dos custos aos produtos diferenciados.

Uma dessas ferramentas é o tempo padrão, que se tornou indispensável, pois possibilita uma análise da capacidade produtiva de um processo, desde que se leve em consideração uma série de aspectos presentes na realidade de uma rotina de trabalho tais como: a fadiga dos funcionários; monotonia do trabalho; necessidades fisiológicas; habilidades e esforços individuais; setup de maquinas. Uma vez observadas e reconhecidas essas limitações, pode-se determinar a capacidade de produção, tempo planejado de operações, bem como alíquotas de distribuição de custos indiretos aos produtos. Segundo Junior (1989), tempo padrão é o tempo necessário para executar uma operação de acordo com um método estabelecido, em condições determinadas, por um operário apto treinado, possuindo uma habilidade média, trabalhando com esforço médio, durante todas as horas do serviço.

Nesse sentido, o processo produtivo poderá ser dividido em várias tarefas segundo a necessidade de se analisar de forma mais detalhada cada operação. Para isso, deve-se levantar os tempos de cada operação em individual fazendo a somatória no final do processo.

A implantação do modelo, entretanto, passou a apresentar dificuldades. A necessidade de se uniformizar os produtos, mesmo que seus tempos padrão fossem diferentes, se tornava cada vez mais necessária. O grande problema consistia em como planejar e organizar a produção de acordo com a capacidade produtiva da fábrica, uma vez que a gama de tempo padrão dos produtos era diversificada. Outro Problema estava em como distribuir os custos indiretos de produção sem arbitrariedade entre os produtos ou serviços produzidos.

Com a metodologia da UP, que é um completo sistema de controles gerenciais fabris, em que se busca medir o valor agregado do "esforço" na busca de cada produto, isso é, permite valorizar cada um em unidades abstratas e constantes no tempo, que somadas representam a quantidade de produção expressa numa única unidade de medida.

De maneira mais clara, a fábrica deixaria de produzir vários produtos diferenciados com tempos padrão diferentes para produzir um único produto a UP, passando todos os controles de produção, custo e rentabilidade a serem operados somente em função desta unidade de produção. (GANTZEL \& ALLORA, 1996)

Caso a empresa opte por utilizar o custeio $A B C$, que quando aplicado na produção tem uma tendência em criar superestruturas de controles de custos devido ao seu detalhamento das atividades, a metodologia da UP permite um controle bem mais simples, uma vez que temos uma única atividade de produção, ou seja, a unidade de produção da UP. Sendo considerada a quantidade de UP produzidas de cada produto como "cost driver", pois as UP's medem a 


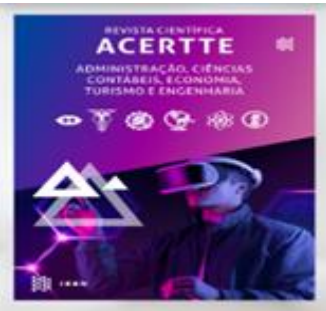

quantidade de trabalho que cada produto absorve na sua fabricação. Porém, deve-se levar em conta que o método da UP é um método padrão, portanto de difícil aplicação nas atividades que geram custos indiretos de fabricação aos produtos, pois as mesmas não se comportam de uma maneira padronizada. (GANTZEL \& ALLORA, 1996).

\section{ASPECTOS PRÁTICOS DA ADOÇÃO DA METODOLOGIA DA UP: UM ESTUDO DE CASO}

Através deste estudo de caso em uma empresa do ramo de confecções, atuante no setor de facção de jeans, estabelecida na cidade de Paraíso do Norte, no Estado do Paraná, procurouse demonstrar os aspectos práticos da adoção da metodologia da UP.

\subsection{Caracterização da empresa}

A empresa objeto do estudo de caso é uma empresa do ramo de confecções, atuante no setor de facção de jeans, ou seja, prestação de serviço de junção das partes, em especial calça jeans, as quais já vêm cortadas dos clientes e acompanhadas de seus aviamentos, ficando a cargo da empresa o processo de costura das peças.

Foi fundada em 2001 na cidade de Cianorte, no Estado do Paraná, transferindo sua sede para a cidade de Maringá em 2008, onde se encontra até hoje. Suas instalações são próprias, consistindo em uma área construída de $1.500 \mathrm{~m} 2$, com um maquinário bem conservado e apresentando boas condições de uso, permitindo uma capacidade mensal estimada de produção de cerca de 30.000 peças mês e empregando cerca de 150 funcionários, atuando em termos de mercado em todo o Estado do Paraná. 


\subsection{Caracterização do processo produtivo}

Figura 02 - Demonstração do processo produtivo da empresa

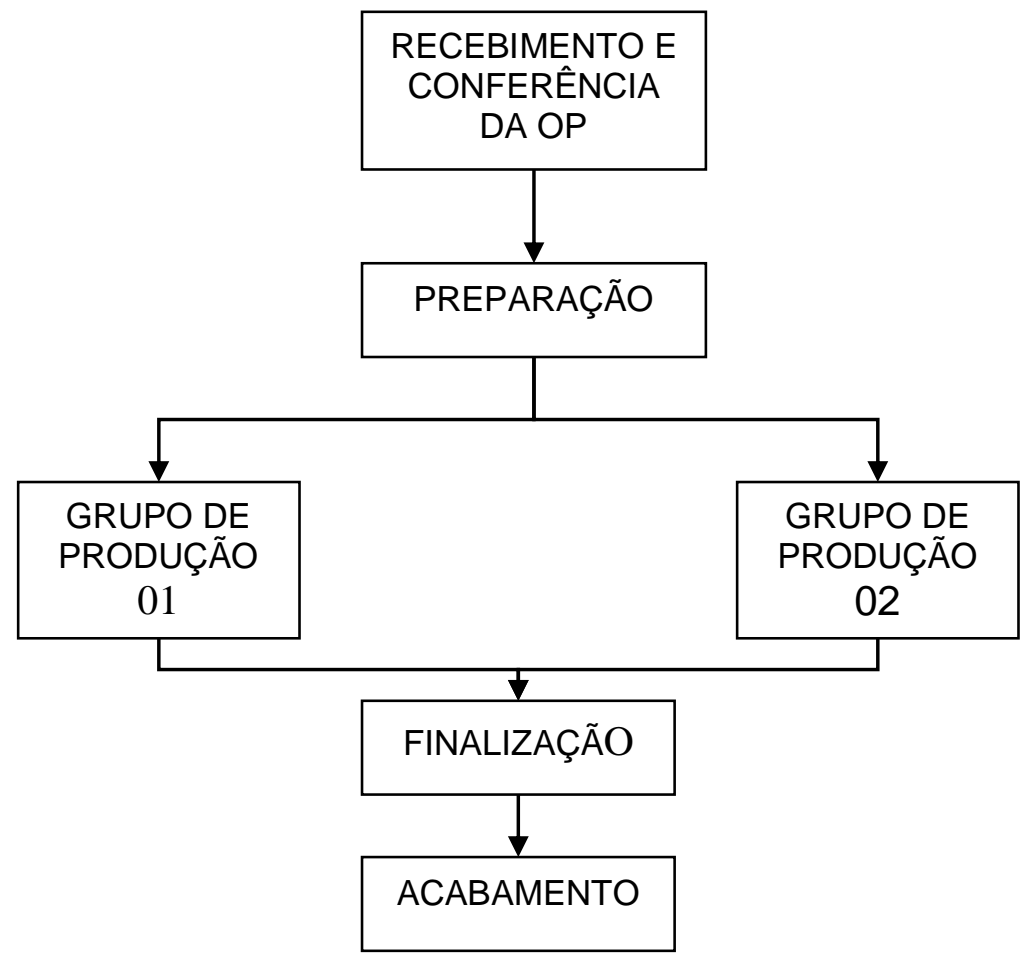

Fonte: Elaborado pelo Autor

Os maquinários e funcionários vinculados à área de fabricação estão distribuídos em células de trabalho, sendo que cada célula tem suas funções definidas e metas estabelecidas com base na metodologia da UP. As células de trabalho apresentadas na empresa são: etiquetação; preparação; grupo de produção 01; grupo de produção 02; finalização; acabamento.

O processo interno da empresa consiste no recebimento das partes cortadas das peças juntamente com seus aviamentos, já separados por ordem de produção, sendo que cada referência a ser produzida é uma ordem de produção diferente. Então, se confere o número de peças da ordem e faz-se a etiquetação da mesma, processo onde são agrupadas e carimbadas as partes, que irão compor a peça. Feito isso, as partes passam a preparação, setor onde serão feitas algumas tarefas de costura com a finalidade de agilizar o processo dos grupos produtivos. Após, são direcionadas aos grupos produtivos que vão juntar, através da costura, as partes para formar a peça. Na sequência, são encaminhadas para o setor de finalização onde são feitos a barra e o caseamento, e por último passando no setor de acabamento, onde é feita a tiragem de linhas e limpeza da peça. O processo produtivo da empresa poderá ser melhor visualizado por intermédio da Figura 02. 


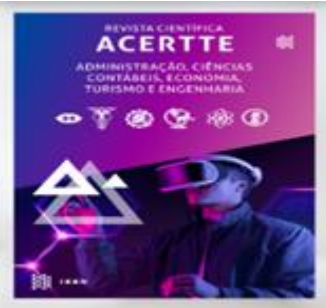

\subsection{Sistema de custos na empresa}

A definição de preço a ser cobrado é determinada pelo mercado, existindo um preço padrão da calça jeans básica que rege o setor de facção permitindo uma pequena oscilação em virtude da qualidade da costura e prazo de entrega. Porém, para a questão de resultado operacional, a empresa usa o sistema de custeio pelo método de absorção, direcionando no final de cada período o montante de custos aos produtos, com base na metodologia da UP. Sendo pertencente ao setor de facção, que consiste na prestação de serviço de costura, não há agregação de custo de matéria-prima ou suprimentos, pois, os mesmos são fornecidos pelos clientes. Os custos maiores são de natureza fixa, chegando a representar em média $90 \%$ dos custos totais, conforme dados fornecidos pela empresa, envolvem gastos com salários, energia elétrica, água, manutenção de máquinas, cestas básicas, material de limpeza, dentre outros. Os custos de natureza variável que representam em média 10\% dos custos totais, envolvem gastos com prêmio de produção e gratificações, que só ocorrem com a superação da meta de produção, que visa a cobrir os custos fixos do período, estabelecida em quantidade de UP.

Há controles que, com base em custos médios de períodos anteriores, projetam o custo diário em valores e em UPs, que se caracterizarão em meta a ser atingida ou até superada através da produção do dia. Esses controlem buscam na realidade trazer um parâmetro de média de produção diária, para que tanto a encarregada da produção como as operadoras possam saber se o desempenho da fábrica, medido através da produção do dia, foi satisfatório em relação à meta de UPs estabelecida e se foi suficiente para trazer saldo positivo em relação ao custo estipulado diariamente. Permite por sua vez, também favorecer uma melhor programação em relação ao resultado operacional diário, uma vez que de posse das ordens e dos graus de dificuldades das peças, há a possibilidade, dentro dos prazos de entrega, de se estar jogando na produção ordem intercaladas. Na prática significa que, uma ordem que necessite de maior tempo de preparação, que levaria a uma redução no número de peças prontas, é intercalada com uma outra que tem um giro mais rápido, equilibrando assim o resultado operacional do dia.

\subsubsection{A metodologia da UP na empresa}

A construção da metodologia de custos UP, na empresa, observou-se os seguintes procedimentos:

- partindo de uma peça básica, uma calça jeans de cinco bolsos sem recortes, foram detalhadas todas as tarefas necessárias para montagem da peça;

- em seguida, tomando 10 operadoras de máquinas de costura, tira-se o tempo de cada tarefa por operadora chegando-se a uma média de tempo por tarefa;

- à soma das médias de cada tarefa é acrescido $18 \%$ do tempo total; esse tempo é estimado pela empresa para suprir as necessidades fisiológicas e fadiga das operadoras e forma o tempo padrão necessário para a confecção de uma calça jeans básica, o que 


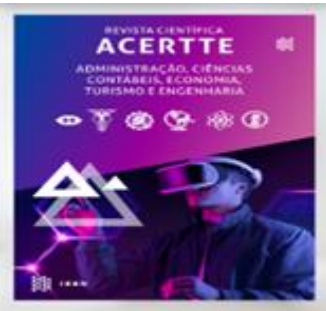

na empresa ficou em 22 minutos, conforme anexo 01.

A empresa conseguiu através da metodologia da UP, uma forma de padronizar os produtos diferenciados, criando uma padronização de processos e uma rotina de tarefas a serem desempenhadas. Dessa forma, quanto maior o número de repetição da tarefa, maior a eficiência da operadora, conseguindo-se, muitas vezes, por repetição diminuir o tempo padrão. Todos os controles da empresa são baseados na quantidade de UPs. Essas determinam as metas a serem alcançadas e medem a eficiência da fábrica, pois, levando-se em conta a UP média dos últimos doze meses de produção, que na empresa é igual a 1,52, a capacidade estimada e meta de produção mensal da fábrica é 45.600 UPs. Dentro desta metodologia da UP e dos controles de custos e resultados, a empresa determinou seu preço padrão por UP que ficou no valor de $\mathrm{R} \$ 3,00$, preço segundo a empresa capaz de trazer uma rentabilidade boa e que o mercado the permite operar.

\subsubsection{Ajustes da UP no processo}

Todas as referências produzidas na empresa são definidas em termo de UP ou como é conhecida pelas operadoras na empresa, por graus de dificuldade, conforme anexo 01 . Se uma referência tem tempo maior que 22 minutos por possuir mais tarefas na sua execução, essas tarefas adicionais são mensuradas em tempo, através da cronoanalise de tempo, e adicionadas ao tempo da peça padrão. Mas se possuem tarefas diferentes da peça básica modelo, é feito uma nova tomada de tempo para esta referência, dentro dos parâmetros acima descritos. Mantendo-se o tempo de 22 minutos como base para definição do grau de dificuldade, é determinando, assim, um fator de quanto tempo a mais esta peça irá necessitar em relação ao tempo da peça padrão. Feito isso, o cronologista faz o balanceamento, ou seja, com o grau de dificuldade previsto no uso da metodologia da UP, determina a quantidade de peças em cada carrinho e o tempo que será necessário para que a célula possa cumprir a meta estabelecida.

\subsubsection{Problemas apresentados com o uso da metodologia da UP}

A análise do fluxo produtivo e operacional, na empresa em estudo, em relação à utilização da metodologia de custos via UP, identificou alguns aspectos que merecem atenção.

Um dos problemas apresentados com o uso da metodologia da UP tem sido o acerto antecipado de preço com o cliente, exigindo uma pessoa com um bom conhecimento prático das tarefas necessárias para a confecção da peça para negociar o preço. Pois o preço, na maioria das vezes, é firmado antes da definição do grau de dificuldade da peça, o que determina a quantidade de UPs. Muitas vezes, depois da tomada de tempo das tarefas já no processo fabril, é necessário renegociar o preço já ajustado.

Observa-se, também, o problema de algumas tarefas, por não fazerem parte da junção das partes no processo fabril, não serem consideradas no tempo total da peça. Esse aspecto é observado quando se verifica a não consideração dos processos de conferência, separação das 


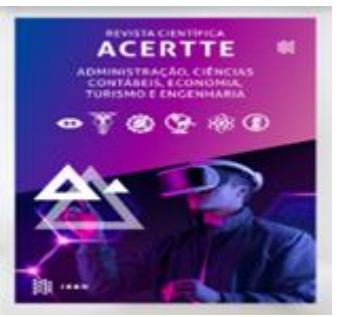

partes e etiquetagem da ordem de produção no cálculo da UP.

Além disso, depara-se, ainda, com o problema do fator humano que não mantém o mesmo rendimento durante toda a jornada de trabalho, isso acrescido também do fator psicológico e emocional que acaba por interferir na motivação pessoal, muitas vezes provocando altos índices de absenteísmo. Verifica-se, ainda, a quebra de máquinas, as quais muitas dessas vitais para o processo fabril, que é de difícil mensuração e atribuição, cujo tempo de parada não é considerado na definição de tempo padrão, e atribuído como perda de produção no resultado da empresa.

\subsection{Análise}

Pode-se analisar que a metodologia da UP caracterizada na empresa através do estudo de caso, trouxe certa comodidade no seu processo fabril, permitindo através da padronização dos produtos diferenciados, uma melhor distribuição de seus recursos produtivos. O que melhorou sua organização e seu planejamento em relação a processos e controles, pois passaram a visar o único produto fabricado denominado UP.

$\mathrm{Na}$ questão de a negociação do preço do serviço por peça ser antecipado, além da necessidade de se ter uma pessoa com bom conhecimento prático das tarefas a empresa poderá desenvolver pasta contendo desenhos de várias referências agrupadas por grau de dificuldade, bem como o detalhamento de suas tarefas e tempos de execução para servirem de suporte para $o$ negociador de preço.

Os processos que até então não fazem parte do tempo padrão, pois não são considerados na metodologia da UP pela empresa, que consistem na conferência, separação das partes e etiquetagem da ordem de produção, poderiam ser incorporados no tempo padrão da peça, usando o mesmo critério de definir as tarefas necessárias para a execução dos processos e tomando o tempo dos operadores.

Quanto ao tratamento dado pela empresa na questão da perda da eficiência, ou seja, uma medição em forma de tabela que representa quanto à empresa deixou de produzir no período em relação a capacidade produtiva da empresa expressa em UPs, essa atribuída à falta de manutenção de rendimento das operadoras durante toda a jornada de trabalho e setup de máquinas. Além disso, verifica-se um alto índice de absenteísmo e quebra de máquinas, as quais, mesmo sendo trocadas de imediato por outras de reservas, acabam por influenciar no tempo do processo, sendo computado pela empresa no resultado do período. No entanto, a empresa poderia utilizar uma média de eficiência, determinada com base em períodos anteriores, a ser acrescentado nos $18 \%$ estabelecidos como perda no rendimento, ou seja, se a eficiência da empresa em relação a capacidade produtiva em número de UPs comparada ao número de UPs feita no período girasse em torno de um média de $85 \%$, conforme tabela 01. 
REVISTA CIENTÍFICA ACERTTE ISSN 2763-8928

METODOLOGIA DA UNIDADE PADRÃO DE TEMPO (UP) EM UMA INDÚSTRIA DE CONFECÇÕES Valdemar Dias dos Santos

Tabela 01 - Demonstrativo do percentual de eficiência da empresa em UP.

\begin{tabular}{|c|c|c|c|c|c|c|}
\hline & NOV/03 & DEZ/03 & JAN/04 & FEV/04 & MAR/04 & ABR/04 \\
\hline CAPACIDADE & 45.600 & 45.600 & 45.600 & 45.600 & 45.600 & 45.600 \\
\hline PRODUÇÃO & 41.938 & 39.889 & 32.300 & 35.318 & 41.206 & 44.600 \\
\hline EFICIÉNCIA & $92 \%$ & $87 \%$ & $71 \%$ & $77 \%$ & $90 \%$ & $98 \%$ \\
\hline
\end{tabular}

Fonte: Elaborado pelo autor

Dessa forma, o percentual a se acrescentar no tempo padrão das tarefas seria $33 \%$, o que equivaleria aos $18 \%$ já estabelecidos como perda no rendimento mais $15 \%$ originado da eficiência média de $85 \%$. Isso demonstra que o tempo padrão de uma peça básica, que fora determinado em 22 minutos, necessitaria de ser acrescentado em mais $15 \%$, elevando esse tempo para 25,3 minutos, e consequentemente alterando o preço final da UPs de $R \$ 3,00$ para $R \$ 3,45$. Isso demonstra que a empresa não apresenta eficácia uma vez que não obtém um retorno adequado na comercialização, utilizando um preço de venda não coerente com seus custos. Nota-se que, apesar da empresa não apresentar resultado negativo na sua apuração de resultado, esse fator identifica perda de oportunidade para obter maiores lucros e melhores condições de investimento.

Cabe observar que o mercado determina o preço de venda e isso pode limitar a capacidade da empresa em ajustar seus preços conforme o custo apresentado. Entretanto, essa identificação propicia condições para que uma análise detalhada e a busca de melhoria nas atividades operacionais, direcionadas principalmente à redução dos custos de produção, sejam iniciadas, minimizando o impacto da perda de $15 \%$ provenientes da ineficiência média produtiva.

\section{CONCLUSÃO}

Procurou-se neste artigo levantar a importância da produção para competitividade e do custo para avaliação da competitividade, o que seria um casamento perfeito, pois o mercado globalizado exige que as empresas produzam cada vez mais, com melhor qualidade e preços competitivos.

Desta forma, a busca de novos métodos de organização de produção se torna constante, a fim de tornar as atividades fabris das empresas mais eficientes. Dentro deste contexto, a principal vantagem proporcionada pela metodologia da UP, em termo de organização e administração da produção, é a padronização do produto, o que permite uma melhor organização e distribuição da produção dentro dos setores produtivos da empresa. Porém, os problemas apresentados com o uso da metodologia da UP no caso em estudo, representam a necessidade da busca incessante de aprimoramento que qualquer processo fabril necessita para se enquadrar numa metodologia de produção.

Assim, haverá sempre a necessidade de se procurar resolver as distorções apresentadas com o uso de uma metodologia, analisando-se os benefícios trazidos com a sua utilização. Porém, a busca de correção das falhas identificadas no método adotado, mantendo-se, principalmente, a 


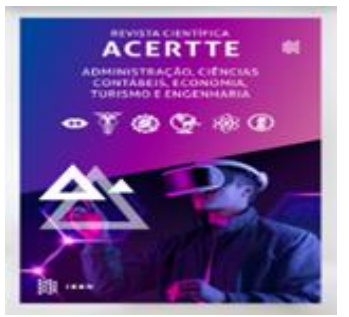

ótica de custo para garantir a lucratividade e o foco de melhoria no processo fabril, deve ser uma orientação contínua.

\section{REVISTA CIENTÍFICA ACERTTE ISSN 2763-8928}

METODOLOGIA DA UNIDADE PADRÃO DE TEMPO (UP) EM UMA INDÚSTRIA DE CONFECÇÕES Valdemar Dias dos Santos

\section{REFERÊNCIAS}

BACKER, Morton; JACOBSEN, Lyle E. Contabilidade de custos: uma abordagem gerencial. São Paulo: Editora MC Graw-Hill, 1984.

FIPECAFI; ANDERSEN, Arthur. Normas e práticas contábeis no Brasil. 2. ed. São Paulo: Atlas, 1995.

GANTZEL, Gerson L.; ALLORA, Valerio. Revolução nos custos. Bahia: Casa da Qualidade Editora,1996.

HAYES, Robert H.; WHEELWRIGHT, Steven C. Competindo através da fabricação. In: MONTGOMERY, Cyntia A.; PORTER, Michael E. Estratégia: A busca da vantagem competitiva. Rio de Janeiro: Campus, 1998.

HORNGREN, Charles Thomas. Contabilidade de custos: um enfoque administrativo. São Paulo: Atlas, 1986.

IOB - Informações Objetivas. Temática Contábil e Balanços. Preços e custos. 2003.

IOB - Informações Objetivas. Temática Contábil e Balanços. O custo da ociosidade na indústria. 2003.

IOB - Informações Objetivas. Temática Contábil e Balanços. Avaliação contábil de estoques industriais: custeio por absorção, custeio direto - ABC - RKW. 2000.

JOHNSON, H. Thomas; KAPLAN, Robert S. Contabilidade Gerencial: a restauração da relevância da contabilidade nas empresas. Rio de Janeiro: Campus, 1993.

JUNIOR, I. F.B.T. Tempos e Métodos. série racionalização industrial. São Paulo: Editora ItysFides Bueno de Toledo Jr. e Cia Ltda, 1989.

LEONE, George Sebastião Guerra. Curso de contabilidade de custos. São Paulo: Atlas, 1997.

MARTINS, Eliseu. Contabilidade de custos. 6. ed. São Paulo: Atlas, 1998.

NAKAGAWA, Masayuki. ABC - custeio baseado em atividades. São Paulo: Atlas, 1994.

PADOVEZE, Clóvis Luís. Contabilidade gerencial: um enfoque em sistema de informação contábil. São Paulo: Atlas, 1997.

TAYLOR, F. W. Princípios de Administração Científica. 8. ed. São Paulo: Atlas, 1990. 